\title{
Indocyanin Green Videoangiography Study of Hemangioblastomas
}

\author{
Yasuo Murai, Koji Adachi, Fumihiro Matano, Kojiro Tateyama, Akira Teramoto
}

\begin{abstract}
Objective: We present herein the intraoperative indocyanin green videoangiography (ICGVAG) findings for three cases of cerebellar hemangioblastoma (HB). Cases: Cerebellar HB was detected in three patients presenting with symptoms of vertigo and/or headaches and diagnosed on the basis of preoperative magnetic resonance imaging (MRI) and cerebral angiographic findings. Preoperative embolization of the tumor feeding artery was not performed in any of the patients. None of the patients underwent any procedure prior to ICGVAG that would affect the ICG findings, such as perilesional hemostatic coagulation or ablation. In each patient, it was possible to judge the approximate location of the tumor in relation to the brain surface and to distinguish the feeding and draining vessels. Following resection of the tumor, ICGVAG images confirmed that the mural nodule had been eliminated. None of the patients required blood transfusion, either during or after the surgery. For each patient, the lesion was pathologically confirmed as HB, postoperative contrast-enhanced MRI confirmed the absence of residual tumor, and diffusion-weighted MRI revealed no ischemic changes. Results: Differentiation of feeding and draining vessels in the region of the lesion is particularly important for successful surgical removal of HB. In the present three patients, ICGVAG findings enabled easy vascular differentiation and were also useful for confirming that there was no residual tumor. Indocyanin green videoangiography was concluded to be useful for safe resection of $\mathrm{HB}$.
\end{abstract}

RÉSUMÉ: Étude d'hémangioblastomes par vidéoangiographie au vert d'indocyanine. Objectif : Nous présentons les observations faites à la vidéoangiographic au vert d'indocyanine (VAVI) effectuée pendant la chirurgie chez trois cas d'hémangioblastomes (HB). Observations cliniques : Un HB a été découvert chez trois patients qui ont consulté pour vertige et/ou céphalée, chez qui le diagnostic a été posé par IRM et angiographie cérébrale avant la chirurgie. Ces patients n'ont pas subi d'embolisation de l'artère qui nourrissait la tumeur au cours de l'intervention ou de manœuvre pouvant influencer les observations à la VAVI avant cet examen, tels la coagulation hémostatique autour de la lésion ou l'ablation de la tumeur. Chez tous les patients, il a été possible d'évaluer le site approximatif de la tumeur en relation à la surface du cerveau et de distinguer les vaisseaux nourriciers des vaisseaux de drainage. Après la résection de la tumeur, les images de la VAVI effectuée pendant la chirurgie ont confirmé que le nodule mural avait été enlevé. Aucun des patients n'a eu besoin d'une transfusion sanguine pendant ou après la chirurgie. Le diagnostic d'HB a été confirmé en anatomopathologie chez tous les patients. L'IRM avec rehaussement de contraste après la chirurgie a confirmé l'absence de tumeur résiduelle et l'IRM pondérée en diffusion n'a pas montré de changements ischémiques. Résultats : La distinction entre les vaisseaux nourriciers et les vaisseaux de drainage dans la région de la lésion est particulièrement importante pour que la résection chirurgicale de l'HB soit un succès. Chez nos trois patients, les observations faites à la VAVI effectuée pendant la chirurgie ont permis de distinguer facilement le système vasculaire et ont également été utiles pour confirmer l'absence de tumeur résiduelle. Nous concluons que la VAVI est utile pour s'assurer que la résection d'un HB est effectuée sans danger.

Can. J. Neurol. Sci. 2011; 38: 41-47

The usefulness of indocyanin green videoangiography (ICGVAG) as a tool for intraoperative monitoring has been reported since about 1998, and its utility is particularly indicated during the neurosurgical treatment of vascular disorders ${ }^{1-10}$. Indocyanin green videoangiography is considered useful for confirming aneurysm occlusion ${ }^{5-7}$, residual blood flow through perforators of approximately $0.3 \mathrm{~mm}$ in diameter ${ }^{5-7}$, and patency of reconstructed blood vessels ${ }^{7}$. Conversely, there have been only a few reports indicating the utility of ICGVAG in relation to tumorous lesions ${ }^{1,2,11,12}$. We report herein the intraoperative ICGVAG findings for three cases of cerebellar hemangioblastoma (HB), and discuss the usefulness of this imaging modality.

\section{Case 1}

A 67-year-old woman presented with vertigo and headaches. Magnetic resonance imaging (MRI) (Figure 1.1) and cerebral angiography led to a diagnosis of a cerebellar HB with the anterior inferior cerebellar artery as its feeding artery.

\footnotetext{
From the Department of Neurosurgery, Nippon Medical School, Tokyo, Japan. Received May 19, 2010. Final Revisions SubmitTed July 7, 2010. Correspondence to: Yasuo Murai, Department of Neurosurgery, Nippon Medical School, 1-1-5 Sendagi, Bunkyo-ku, Tokyo, 113-86, Japan.
} 
Craniotomy was performed via a lateral suboccipital approach. Following incision of the dura, the cisterna magna was opened and the cerebrospinal fluid was aspirated. The fluid contents of the cyst were also aspirated and the operative field was secured. The site of the lesion was confirmed from above the arachnoid (Figure 1.2). Indocyanin green (ICG), at $10 \mathrm{mg}$ ( $25 \mathrm{mg} / 10 \mathrm{ml}$ of distilled water), was intravenously infused via a peripheral blood vessel, flushing was performed with $10 \mathrm{ml}$ of physiological saline, and visualization was achieved from $12 \mathrm{sec}$ after ICG infusion. Visualization of the lesion (Figure 1.3) began at about the same time as the arterial phase, while the draining vein (Figure 1.4) was visualized before the venous phase but clearly after the contrast findings for the lesion. Thus, the feeding and

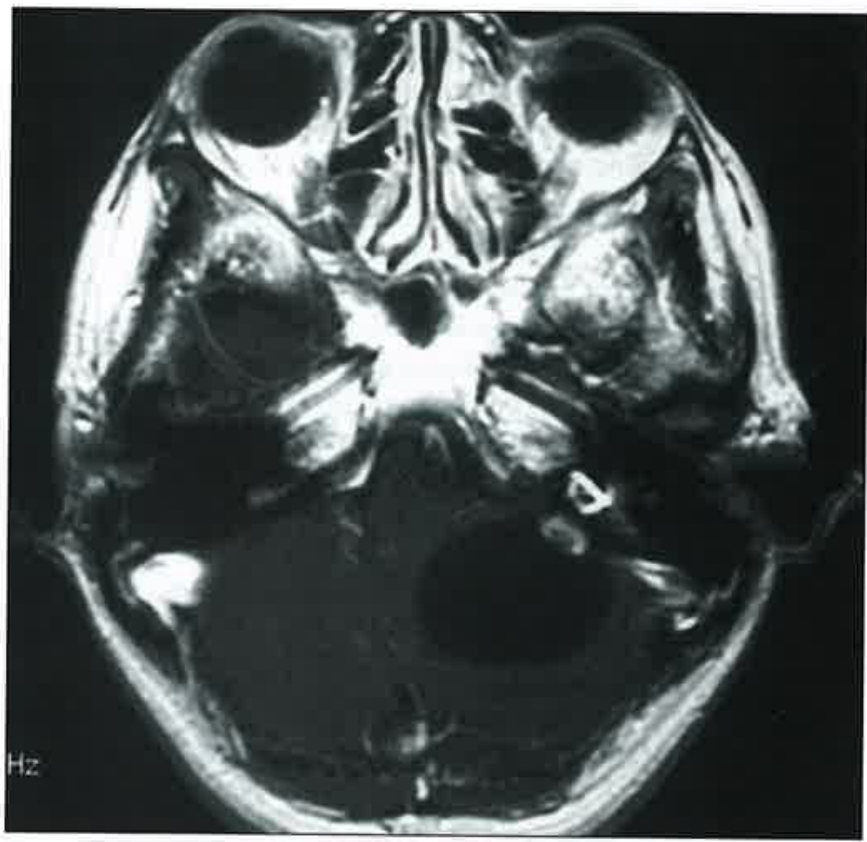

Figure 1.1: Contrast-enhanced MRI showing a cyst in the left cerebellar hemisphere, and an enhanced lesion in contact with the wall near the cerebeller surface.

draining vessels could be clearly distinguished. Indocyanin green videoangiography (Figure 1.5) performed following tumor resection (Figure 1.6) showed no abnormal staining that would correspond to a tumor shadow. Postoperative contrast-enhanced MRI on Day 2 after resection also confirmed that the tumor lesion had been totally removed. The post operative course was uneventful and the tumor was pathologically diagnosed as $\mathrm{HB}$.

\section{Case 2}

A 29-year-old man presented with headaches. Magnetic resonance imaging (Figure 2.1) and cerebral angiography led to a diagnosis of a cerebellar $\mathrm{HB}$ with the posterior inferior cerebellar artery (PICA) as its feeding artery. Craniotomy and C1 laminectomy was performed via a midline suboccipital

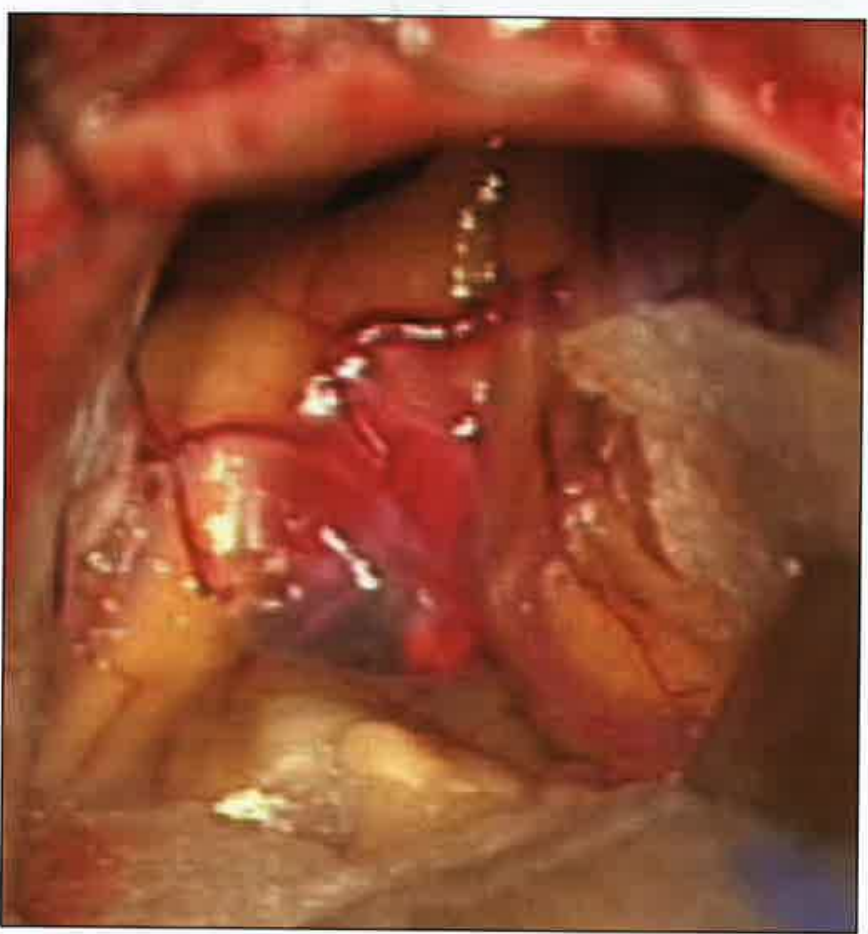

Figure 1.2: The lesion site is unclear in the visual field of an ordinary microscope. It is difficult to distinguish the feeders and the drainers.

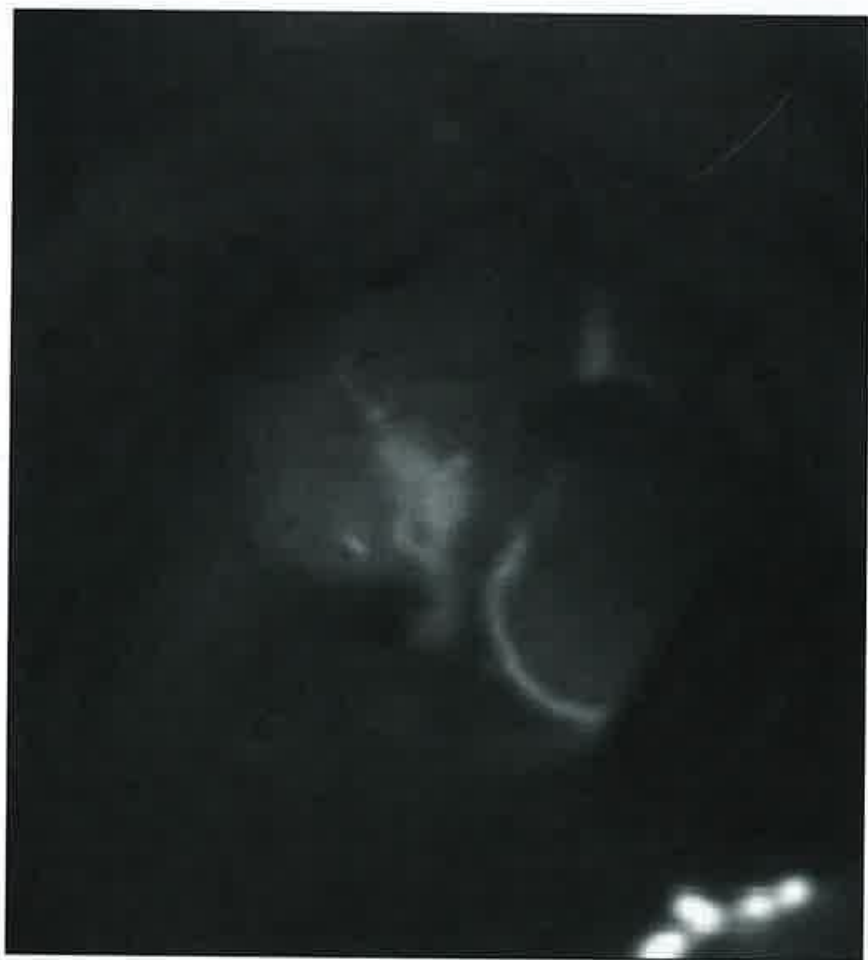

Figure 1.3: An ICGVAG image taken $12 \mathrm{sec}$ after ICG infusion. The tumor lesion area is visualized; however, the draining vessel has not yet been enhanced. 


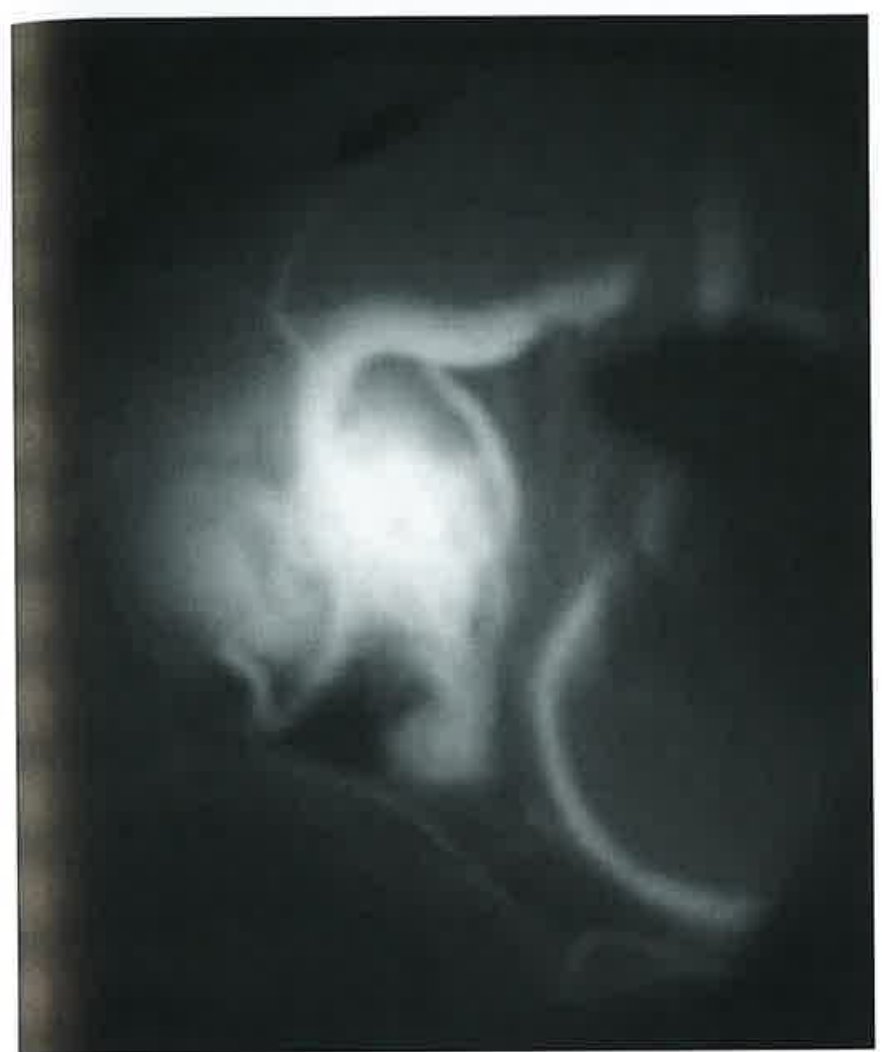

Figure 1.4: An ICGVAG image taken $18 \mathrm{sec}$ after ICG infusion. The draining vessel has been enhanced.

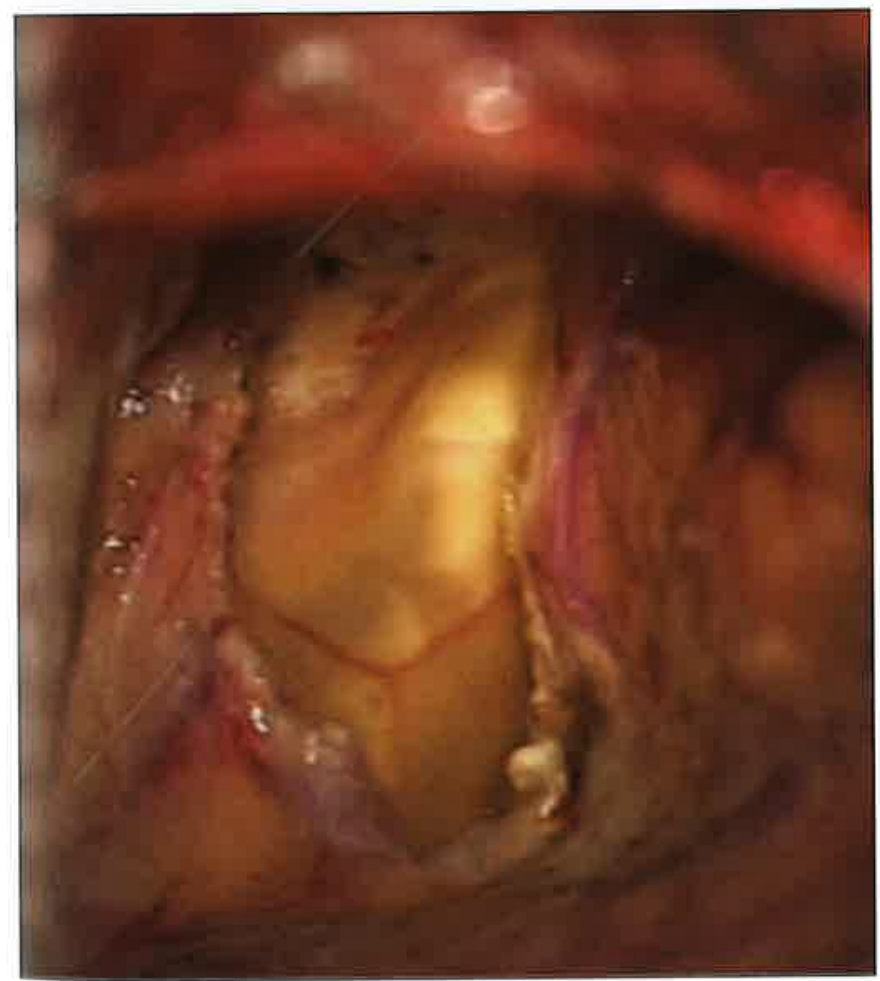

Figure 1.6: The microscopic findings indicate residural tumor.
Figure 1.5: An ICGVAG image taken following resection of the HB lesion. There is no enhanced area in the cyst wall.

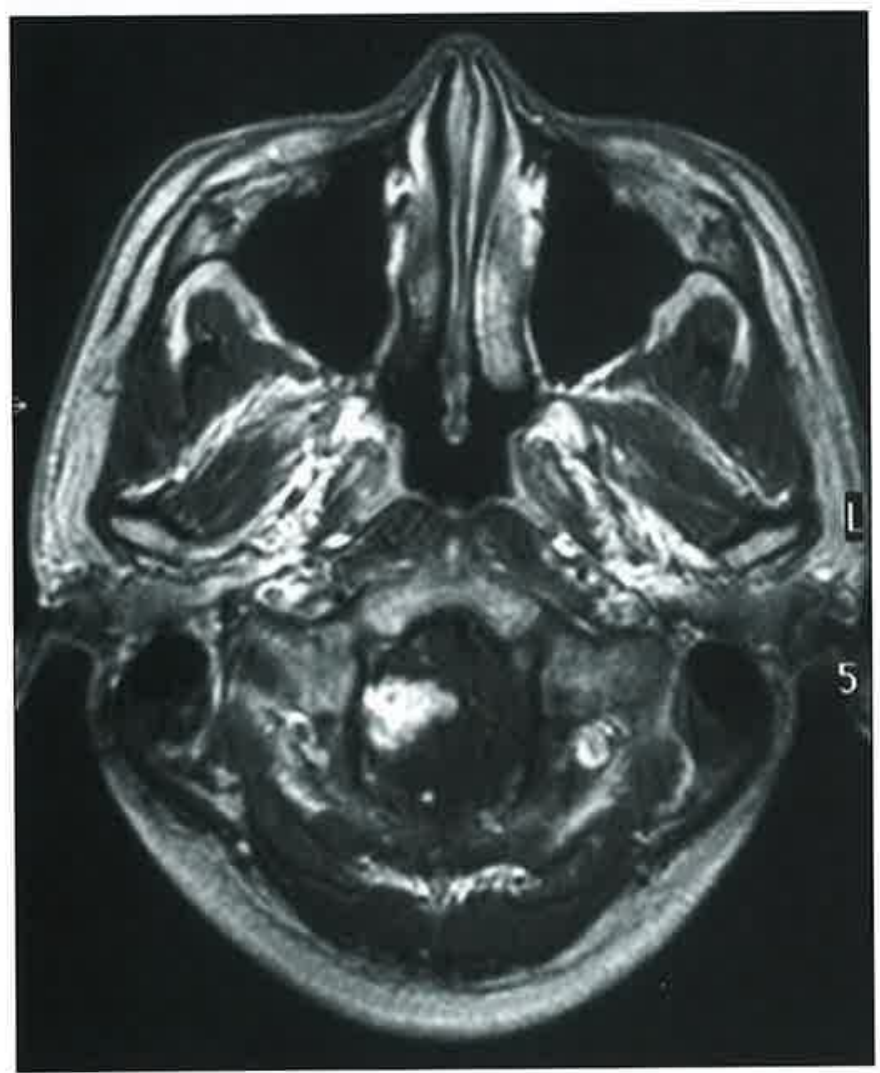

Figure 2.1: Contrast-enhanced MRI showing a cyst in the right cerebellar tonsil. 


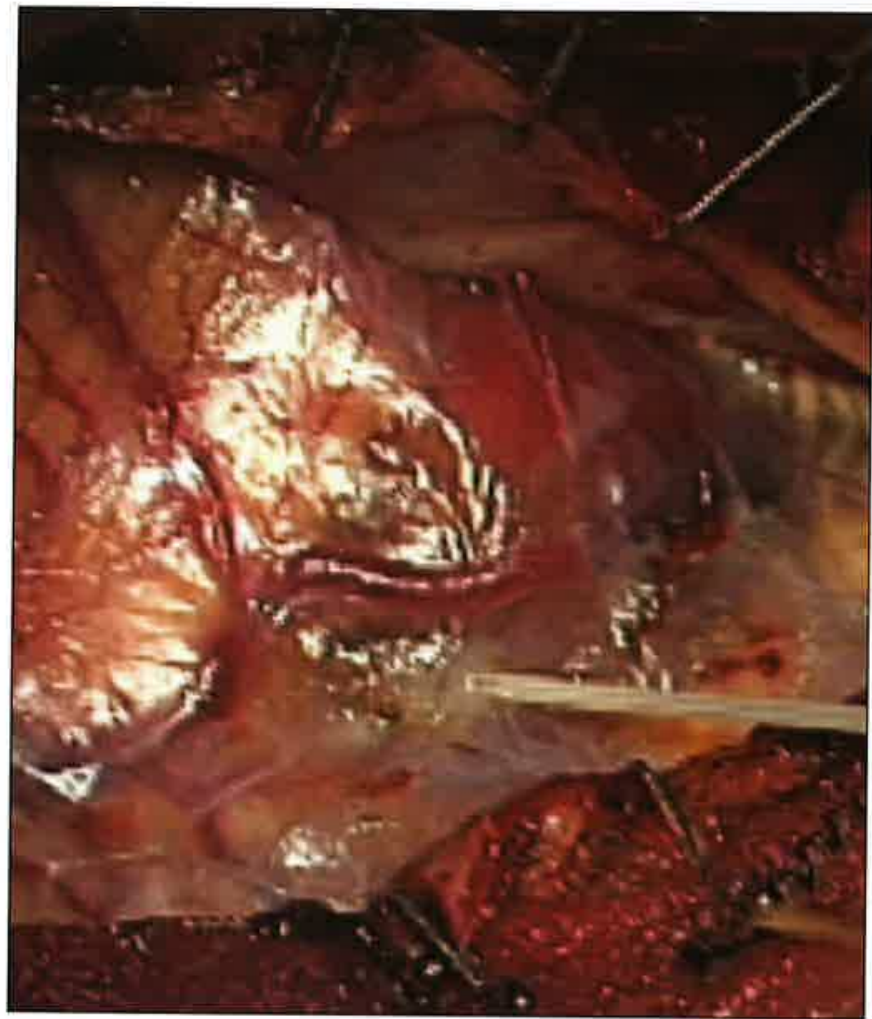

Figure 2.2: The lesion site is unclear in the visual field of an ordinary microscope. It is difficult to distinguish the feeders and the drainers.

approach. Ventricular drainage was performed prior to incision of the dura. Following dural incision, the general location of the lesion was confirmed from above the arachnoid (Figure 2.2). ICG, at $12 \mathrm{mg}$ (25 mg/10 $\mathrm{ml}$ of distilled water), was intravenously infused via a peripheral blood vessel, flushing was performed with $10 \mathrm{ml}$ of physiological saline, and visualization was achieved from $22 \mathrm{sec}$ after ICG infusion. Visualization of the lesion (Figure 2.3) began at about the same time as the arterial phase. The draining vein ran along the top of the tumor body, and was therefore confirmed as a filling defect. The delayed phase of ICGVAG (Figure 2.4) suggested the position of the draining vein. ICGVAG (Figure 2.5) performed following tumor resection (Figure 2.6) revealed no abnormal staining that would correspond to a tumor shadow. Postoperative contrast-enhanced MRI on day 43 after resection also confirmed complete removal of the tumor lesion. The postoperative course was uneventful and the tumor was pathologically diagnosed as HB.

\section{Case 3}

A 56-year-old man presented with headaches. Magnetic resonance imaging (Figure 3.1) and cerebral angiography led to a diagnosis of a cerebellar HB with the PICA as its feeding artery. Craniotomy was performed via a midline suboccipital approach. Ventricular drainage was performed prior to incision of the dura. Following dural incision, the location of the tumor from the surface of the cerebellum was unclear (Figure 3.2). $\mathrm{ICG}$, at $12 \mathrm{mg}(25 \mathrm{mg} / 10 \mathrm{ml}$ of distilled water), was

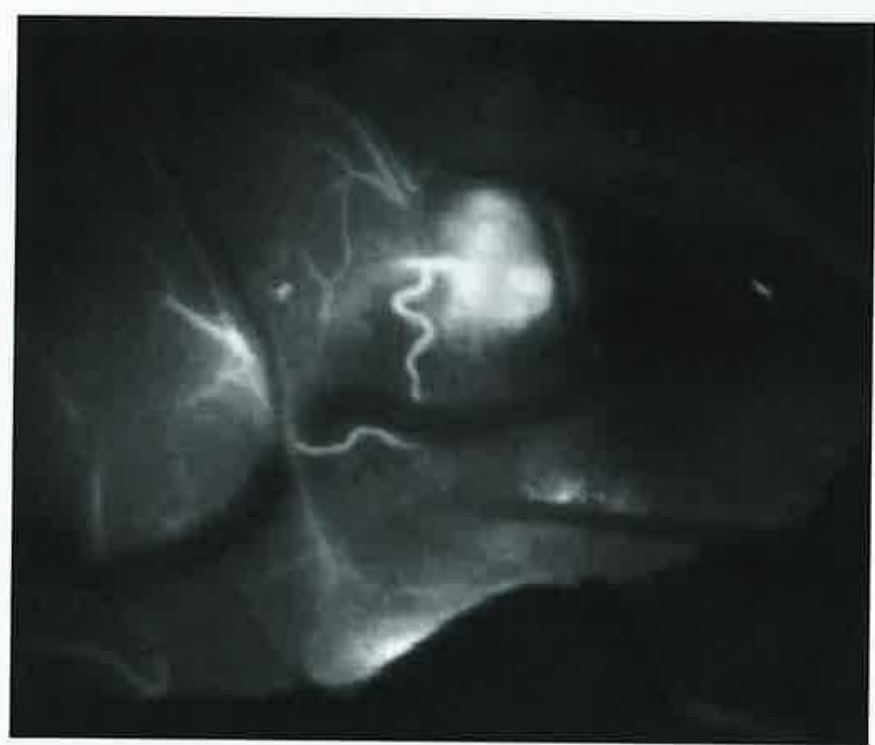

Figure 2.3: An ICGVAG image taken $22 \mathrm{sec}$ after ICG infusion. The tumor lesion area is visualized; however, the draining vessel has not yet been enhanced.

intravenously infused via a peripheral blood vessel, and flushing was performed with $10 \mathrm{ml}$ of physiological saline. A dilated and tortuous abnormal vessel was confirmed on the cerebellar surface (Figure 3.3) $18 \mathrm{sec}$ after ICG infusion, and the tumor location gradually became stained and defined. Prior to ICGVAG, the extent of tumor was not confirmed, however, postICGVAG, extent of tumor was clearly indicated. The delayed phase of ICGVAG (Figure 3.4) suggested the position of the

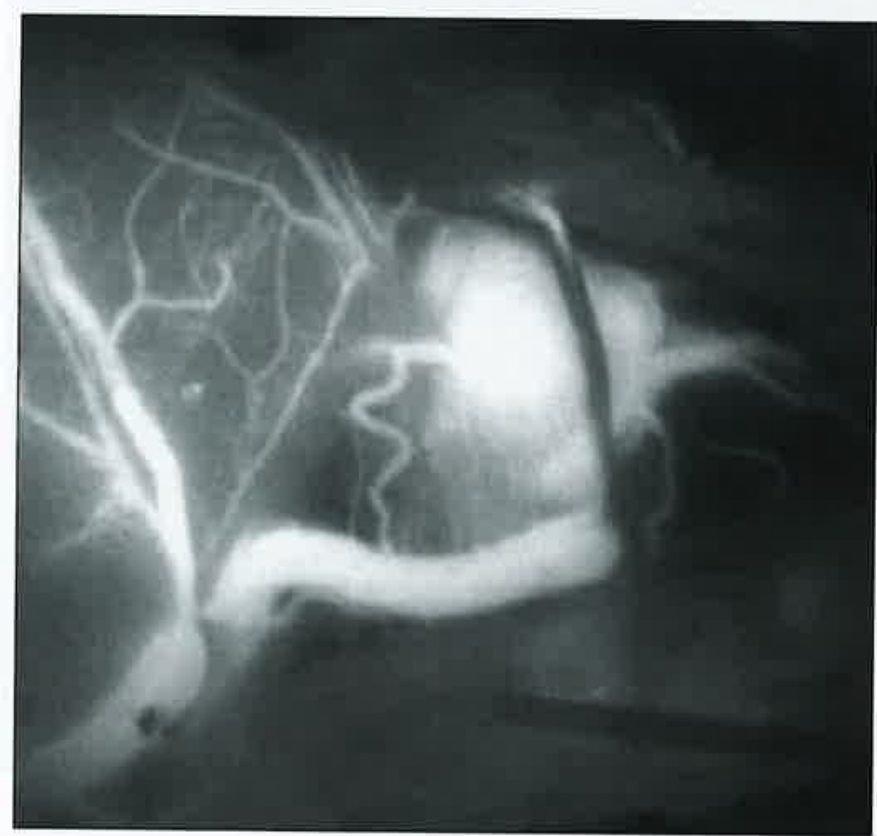

Figure 2.4: An ICGVAG image taken $25 \mathrm{sec}$ after ICG infusion. The draining vessel has been enhanced. 


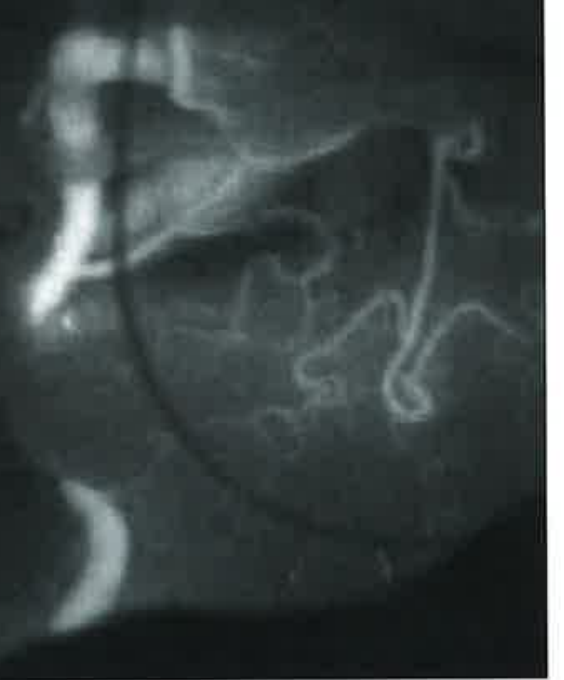

Figure 2.5: An ICGVAG image taken following resection of the $H B$ lesion. There is no enhanced area in the cyst wall.

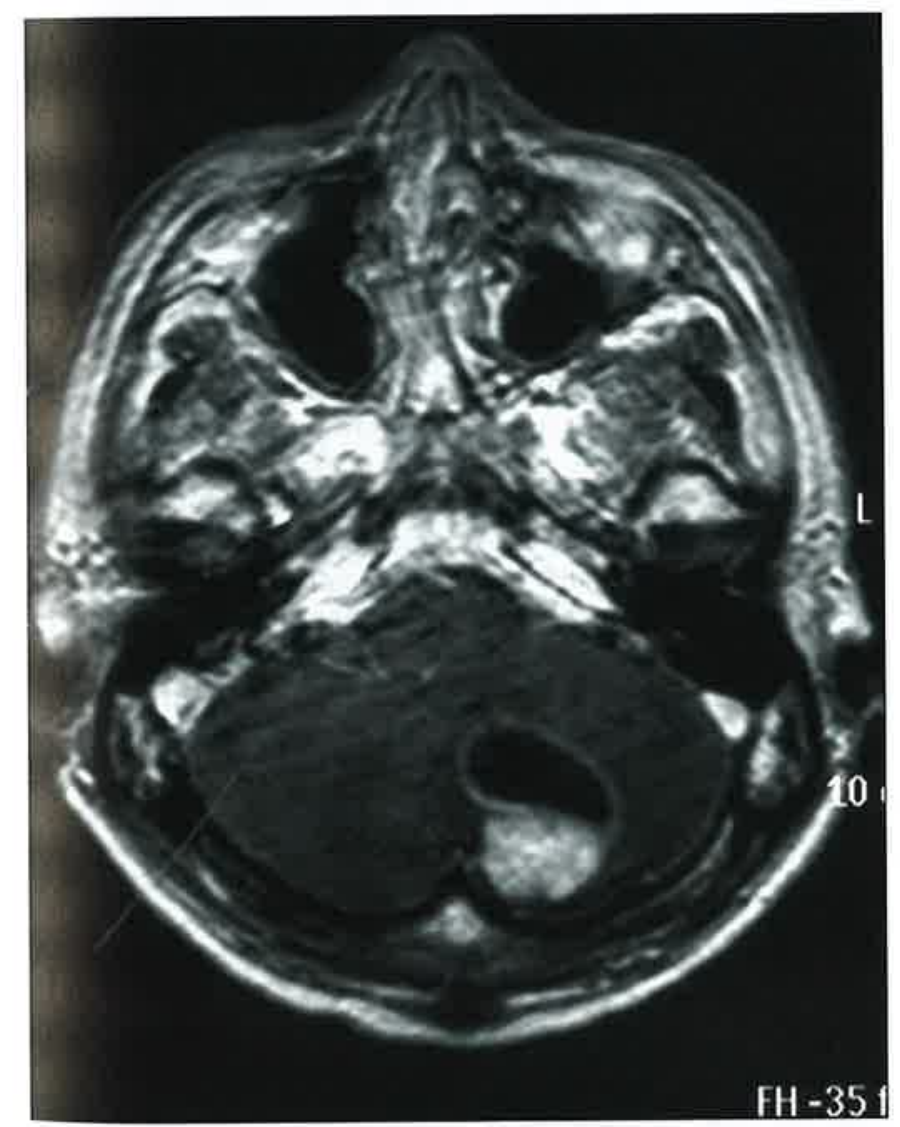

Figure 3.1: Contrast-enhanced MRI showing a cyst in the left cerebellar hemisphere, and an enhanced lesion in contact with the wall near the cerebeller surface.

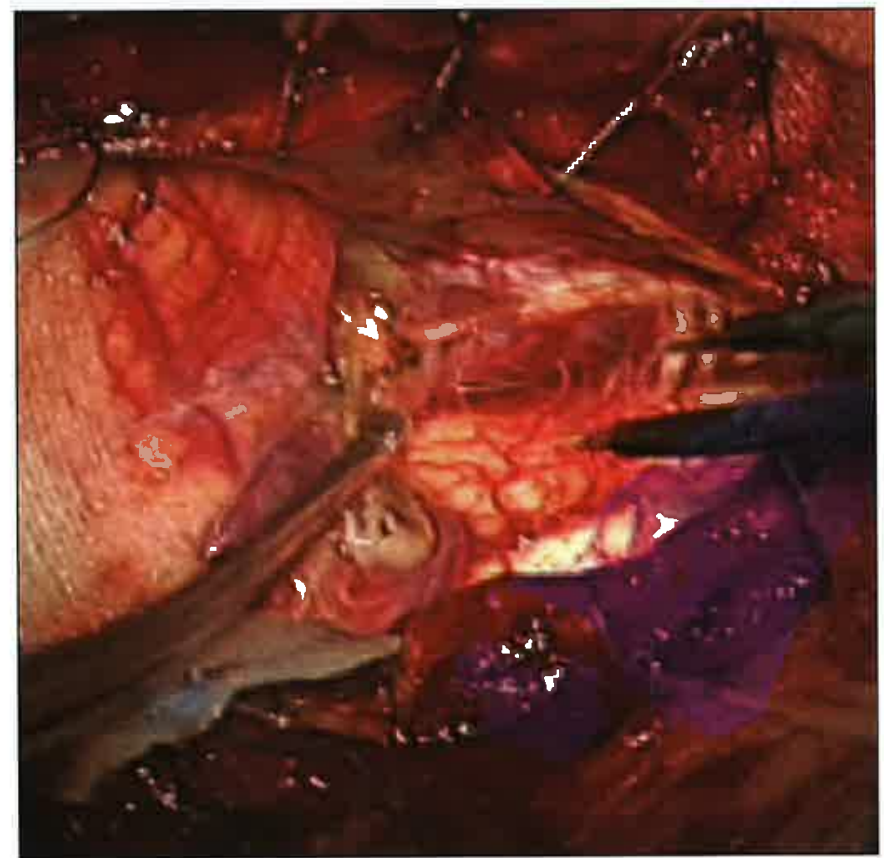

Figure 2.6: The microscopic findings indicate residural tumor:

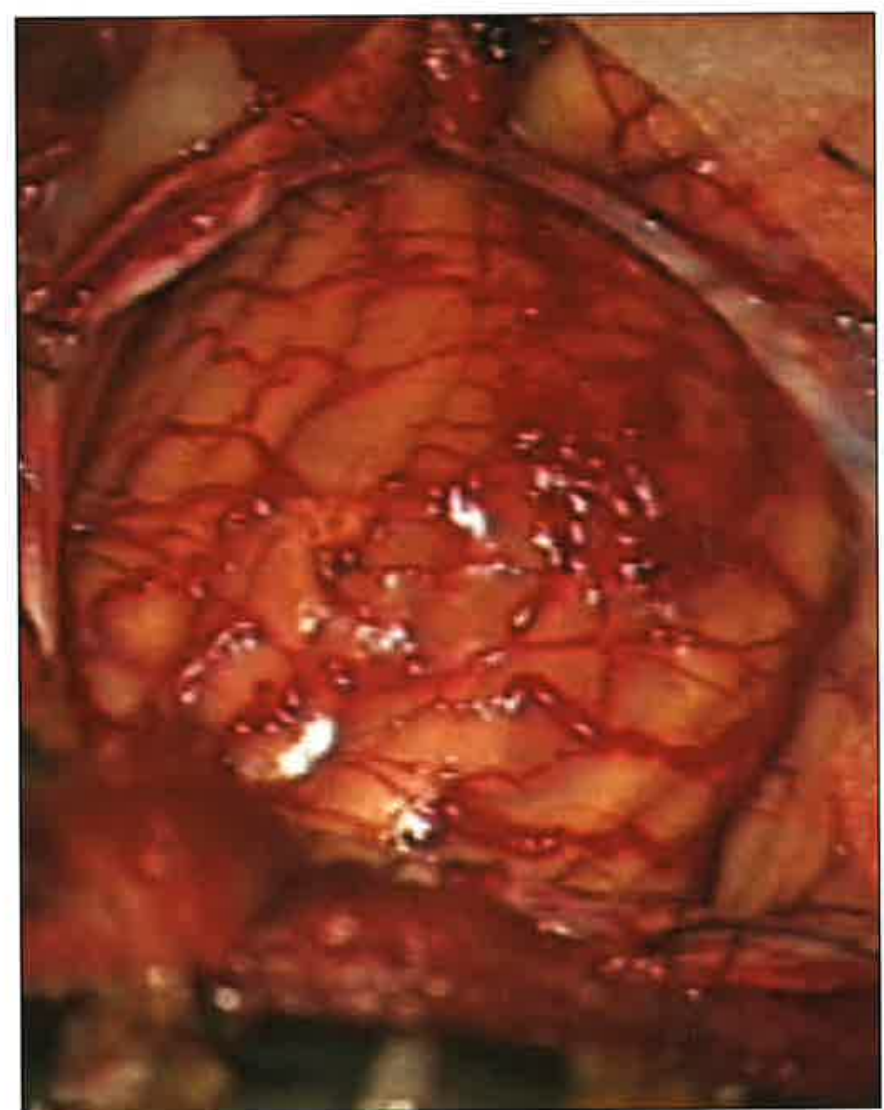

Figure 3.2: The lesion site is unclear in the visual ficld of an ordinary microscope. It is difficult to confirm the location of the tumor fiom the surface of the cerebellum and to distinguish the feeders and the drainers. 


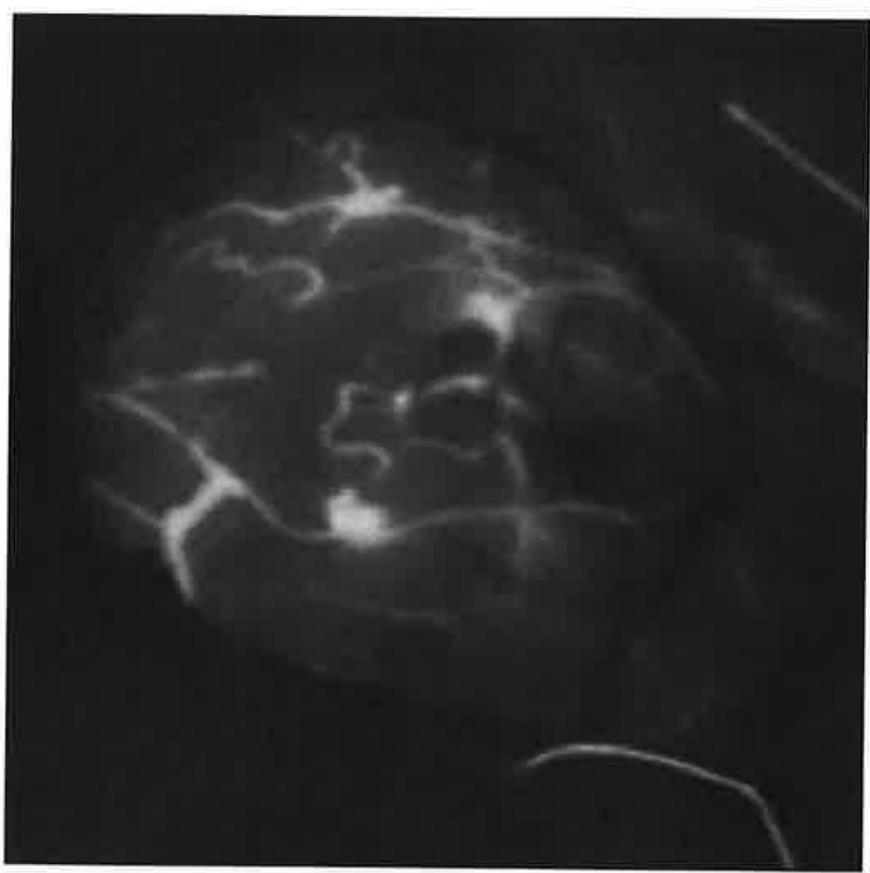

Figure 3.3: An ICGVAG image taken 18 sec after ICG infusion. The dilated and tortuous abnormal vessel was confirmed on the cerebellar surface.

draining vein. Postoperative contrast-enhanced MRI on Day 1 after resection confirmed complete removal of the tumor lesion. The postoperative course was uneventful and the tumor was pathologically diagnosed as $\mathrm{HB}$.

\section{Discussion}

In 2003, Raabe et $\mathrm{al}^{6}$ reported their clinical experience with ICGVAG as an intraoperative image diagnostic technique for evaluating cerebral perfusion. In particular, with regard to its usefulness in comparison with intraoperative cerebral angiography, ICGVAG is reported to be an easy, rapid and inexpensive modality ${ }^{1-9}$. With respect to intracranial lesions, ICGVAG is useful in cases including aneurysm, vascular reconstructive surgery, and cerebral infarction ${ }^{1-9}$. There have also been reports of the utility of this imaging modality in a small number of patients with tumorous lesions $s^{1,2,11,12}$. Britz et al ${ }^{1}$ and Hansen et $\mathrm{al}^{2}$ reported that ICG may provide visual enhancement of tumor margins in a rat glioma model, thus aiding radical resection. However, there have been no clinical reports regarding the application of ICGVAG in patients with HB. Indocyanin green videoangiography has been indicated during the surgical resection of cerebral arteriovenous malformations (AVM) $)^{3,6}$. Hemangioblastoma is angiographically similar to such malformations; therefore, it is likely that ICGVAG can be conveniently applied to the surgical removal of HB. In the present three cases, ICGVAG findings clearly visualized the HB, feeding artery and draining veins, thus aiding clarification of tumor borders and decreasing the extent of necessary resection.

Hemangioblastoma lesions are more often present as mural nodules located close to the brain surface ${ }^{13-15}$ rather than

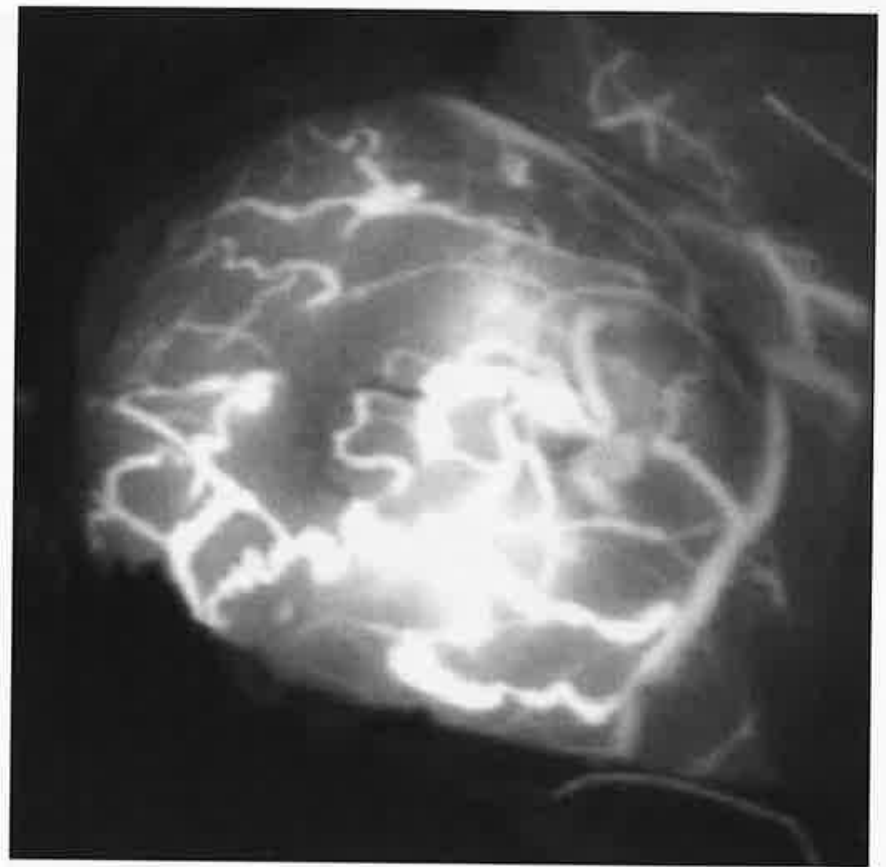

Figure 3.4: Delayed phase of ICGVAG, taken 21 sec after ICG infusion, suggested the draining vein.

presenting as cysts, HB lesions are more often found as mural nodules located close to the brain surface. The lesion is partially exposed on the cerebellum surface, and the tumor blood vessels form an abnormal vascular network on the brain surface directly above. These anatomical characteristics explain why ICGVAG is convenient for intraoperative examination of HB. In the case of AVM, which are often located deep in the brain, it is necessary to employ cerebral angiography, which is a radiographic test capable of seeing through the brain. In comparison with cerebral angiography, ICGVAG, which is a fluorescence test, is unable to depict the lesion site if the light is blocked by the brain parenchyma $^{6-9}$. Therefore, a lesion in the brain parenchyma can only be observed with ICGVAG if the perilesional tissue is first removed ${ }^{10,11}$. Indocyanin green videoangiography is currently under evaluation for future application in the differential diagnosis of image findings ${ }^{10,11}$, and the present cases provide important examples of intraoperative ICGVAG imaging of HB.

In addition to confirming the location of the tumor body, successful resection of HB requires differentiation between the feeding and draining vessels and evaluation of the presence/ absence of residual tumor tissue ${ }^{13,14}$. Wang et $\mathrm{al}^{14}$ reported that their surgical principle for HB is similar to that for AVM: selective division of feeding arteries, preservation of the main draining veins, and protection of vessels across the tumor surface during dissection are crucial for total tumor resection. Cleavage of the main draining veins, which are extremely dilated, should be carried out at the last moment. Jagannathan et al ${ }^{13}$ also reported that care should be taken to coagulate and sharply interrupt vessels individually as they enter or leave the tumor capsule, and that vessels supplying the tumor should be 
cauterized and sharply transected. With regard to distinguishing between the feeding and draining vessels, the blood in the draining vessels is predominantly arterial blood due to shunting, while both of blood vessels are abnormal rather than ordinary vessels. Therefore, it is not easy to distinguish between the feeding and draining vessels on the basis of their appearance. However, ICGVAG allows ready differentiation because it permits observation of the direction and time-flow of the blood flow $^{3-9}$. This may also contribute to the prevention of intraoperative blood loss. Wang et $\mathrm{al}^{15}$ reported the usefulness of intraoperative sonographic guidance and Utsuki et al ${ }^{12}$ suggested that fluorescence diagnosis performed using 5-aminolevulinic acid can inform the choice of removing HB lesions. In addition, the existence of a residual tumor can be confirmed on the basis of marked contrast enhancement of the lesion with ICGVAG.

\section{CONCLUSION}

Differentiation of feeding and draining vessels in the cerebeller $\mathrm{HB}$ is particularly important for successful surgical removal. In the present three patients, ICGVAG findings enabled easy vascular differentiation and were also useful for confirming that there was no residual tumor. ICGVAG was concluded to be useful for safe resection of cerebeller HB.

\section{REFERENCES}

1. Britz GW, Ghatan S, Spence AM, Berger MS. Intracarotid RMP-7 enhanced indocyanine green staining of tumors in a rat glioma model. J Neurooncol. 2002;56(3):227-32.

2. Hansen DA, Spence AM, Carski T, Berger MS. Indocyanine green (ICG) staining and demarcation of tumor margins in a rat glioma model. Surg Neurol. 1993;40(6):451-6.

3. Killory BD, Nakaji P, Gonzales LF, Ponce FA, Wait SD, Spetzler RF. Prospective evaluation of surgical microscope-integrated intraoperative near-infrared indocyanine green angiography during cerebral arteriovenous malformation surgery. Neurosurgery. 2009;65(3):456- 62 .

4. Kuebler WM, Sckell A, Habler O, et al. Noninvasive measurement of regional cerebral blood flow by near-infrared spectroscopy and indocyanine green. J Cereb Blood Flow Metab. 1998;18(4): 445-56.
5. Murai Y, Adachi K, Koketsu K, Teramoto A. [Noninvasive measurement of cortical blood flow by microscope-integrated intraoperative indocyanine green videoangiography.] Jpn J Neurosurg. 2009;18(3): 839-43. Japanese.

6. Raabe A, Beck J, Gerlach R, Zimmermann M, Seifert V. Nearinfrared indocyanine green video angiography: a new method for intraoperative assessment of vascular flow. Neurosurgery. 2003; 52(1):132-9.

7. Raabe A, Nakaji P, Beck J, et al. Prospective evaluation of surgical microscope-integrated intraoperative near-infrared indocyanine green videoangiography during aneurysm surgery. J Neurosurg. 2005; 103(6):982-9.

8. Woitzik J, Horn P, Vajkoczy P, Schmiedek P. Intraoperative control of extracranial-intracranial bypass patency by near-infrared indocyanine green videoangiography. J Neurosurg. 2005;102 (4):692-8.

9. Woitzik J, Peña-Tapia PG, Schneider UC, Vajkoczy P, Thomé C. Cortical perfusion measurement by indocyanine-green videoangiography in patients undergoing hemicraniectomy for malignant stroke. Stroke. 2006;37(6):1549-51.

10. Takagi Y, Kikuta K, Nozaki K, Sawamura K, Hashimoto N. Detection of a residual nidus by surgical microscope-integrated intraoperative near-infrared indocyanine green videoangiography in a child with a cerebral arteriovenous malformation. J Neurosurg. 2007; 107(5 Suppl):416-8.

11. Sakatani K, Kashiwasake-Jibu M, Terada H, Zuo H. Development of surgical confocal scanning microscope for intra-operative imaging of brain tumors using near infrared fluorescence: technical note. Neurol Res. 2000; 22(5):533-6.

12. Utsuki S, Oka H, Sato K, Shimizu S, Suzuki S, Fujii K. Fluorescence diagnosis of tumor cells in hemangioblastoma cysts with 5-aminolevulinic acid. J Neurosurg. 2010;112(1): $130-2$.

13. Jagannathan J, Lonser RR, Smith R, DeVroom HL, Oldfield EH. Surgical management of cerebellar hemangioblastomas in patients with von Hippel-Lindau disease. J Neurosurg. 2008;108 (2):210-22.

14. Wang C, Zhang J, Liu A, Sun B. Surgical management of medullary hemangioblastoma. Report of 47 cases. Surg Neurol. 2001;56 (4):218-27.

15. Wang Y, Wang Y, Gao X, Wang Y. Intraoperative sonographically guided resection of hemangioblastoma in the cerebellum. J Clin Ultrasound. 2006;34(5):247-9. 